Research Article

\title{
Seismic Performance of Masonry Walls Built with New Type of Fired Shale Hollow Blocks
}

\author{
Jian Wu, ${ }^{1}$ Liangcheng Zeng, ${ }^{1}$ and Bo Wang $\mathbb{D}^{2}$ \\ ${ }^{1}$ Shaanxi Key Laboratory of Safety and Durability of Concrete Structures, Xijing University, Xi'an 710123, China \\ ${ }^{2}$ School of Civil Engineering, Chang'an University, Xi'an 710061, China \\ Correspondence should be addressed to Bo Wang; chnwangbo@chd.edu.cn
}

Received 21 November 2019; Revised 8 February 2020; Accepted 15 May 2020; Published 7 August 2020

Academic Editor: Melina Bosco

Copyright $(2020$ Jian Wu et al. This is an open access article distributed under the Creative Commons Attribution License, which permits unrestricted use, distribution, and reproduction in any medium, provided the original work is properly cited.

\begin{abstract}
This paper presents the cyclic loading test results of a new type of fired shale hollow block masonry walls. Six specimens were designed including two specimens without reinforcements (bare walls) and four specimens constrained by structural columns (reinforced walls). The influences of aspect ratio, vertical compressive stress, and structural column on the seismic performance of the specimens were investigated. The failure mode, bearing capacity, ductility, stiffness degradation, and energy dissipation of specimens were analyzed. The results showed that the crack patterns of specimens changed from the horizontal straight shape (bare walls) to " $\mathrm{X}$ " shape (reinforced walls), and the corresponding bearing capacity, ductility, stiffness degradation, and energy dissipation of the specimens were improved. With the increase of the vertical compressive stress, the ductility and the secant stiffness of the specimens increased. Moreover, with the decrease of aspect ratio, the bearing capacity and secant stiffness of the masonry walls increased, while the energy dissipation capacity decreased. This paper confirms that fired shale hollow block walls could meet the seismic requirements through appropriate design, which could promote the application of this new type of block in civil engineering.
\end{abstract}

\section{Introduction}

As a type of traditional masonry material, fired clay brick has been widely used in the world for thousands of years. For instance, clay has been used to manufacture sintered bricks for more than 3000 years in China [1]. The annual production of fired clay bricks is about 600 billion pieces in China, which is approximately equivalent to a farmland with 0.47 billion square meters [2]. Accordingly, the application of shale as masonry material has an adverse effect on the environment. Hence, researchers begin to investigate the possibility of using natural materials and waste as masonry materials, such as sedimentary rocks (e.g., tuffs and shale) [3-6], and agricultural or industrial waste (e.g., the husk of crops, sawdust, sludge, coal fly ash, and GRP dust) [7-13]. These studies show that it is possible to replace clay entirely or partially as masonry wall materials by other materials. Among these materials, the shale, which is created by dehydration and cementation of clay, gradually becomes a research hotspot. It is widely distributed in western China and easy to be exploited. Therefore, the application of shale could effectively reduce the cost of raw materials and protect the environment [14].

There have been some researches on the shale as building materials. Parras et al. [15] introduced the mineralogical and ceramic characteristics of three Ordovician shales from the Ciudad Real province, and firing tests were conducted. The results indicated that the optimal sintering temperature was between $1100^{\circ} \mathrm{C}$ and $1150^{\circ} \mathrm{C}$, and the linear shrinkage and water absorption met the requirement of specifications for the manufacture of red stoneware. Similar tests were conducted by Hajjaji and Khalfaoui [16]. The above two test results confirm that the ceramic properties of shale under high temperatures meet the requirement of fired bricks. Li et al. [17] investigated the sintering temperature on the characteristics of fired shale brick mixed with industrial waste. The test results presented that with the increase of sintering temperature, the water absorption and apparent 
porosity decreased, and the shrinkage increased, indicating that the sintering temperature has a significant influence on the brick properties. This result was similar to the study of Liu [18]. Moreover, the water absorption of brick could significantly affect the durability of the bricks; thus, Griffin et al. [19] measured the sorptivity, porosity, and pore size of five types of fired bricks, the result showed that water sorptivity was related to whether the organic carbon content of shale was burned out during the firing process.

Compressive strength is an important index to determine whether the fired shale brick could be used in engineering. Besides, fired shale bricks are often manufactured with a high void ratio, which has adverse effects on the compressive strength of brick. Xie [20] studied the effect of hole type, length-width ratio, arrangement type and quantity of hole, and void ratio on the thermal and mechanical performances of fired shale hollow block, and the compressive strength of the block with best thermal insulation performance was $5.35 \mathrm{MPa}$, which met the requirements of Chinese standard GB/T 13454-2014 [21]. The compressive strength of the fired shale hollow block could even reach a value of $11.1 \mathrm{MPa}$ [22], indicating that the mechanical properties of fired shale block are reliable.

Besides the compressive strength, the seismic response of masonry walls is a more effective way to reflect the failure mode of masonry structures. At present, there are few studies on the mechanical properties of fired shale block walls. Therefore, this paper mainly refers to the testing of walls made of fired clay bricks or concrete blocks. Salmanpour et al. [23] investigated the displacement capacity of unreinforced masonry walls, in which the vertical precompression and aspect ratio were considered. The results presented that the displacement decreased with the increase of vertical precompression, while the decrease of aspect ratio resulting in an increase in the displacement of walls. Sajid et al. [24] studied the effects of vertical stress and flanges on the lateral in-plane response of unreinforced masonry walls. The experimental results indicated that both vertical stresses and flanges incorporation significantly improved the seismic performance of walls. Similar experiment was also conducted by Chi et al. [25]. Compared with unreinforced masonry walls, the reinforced masonry walls exhibit better seismic performance. The materials of reinforced components could be reinforced concretes or steels. Markulak et al. [26] introduced the behavior of steel frames with different types of blocks and found that the failure mode of specimens exhibited ductility characteristics. Wang et al. [27] carried out an experimental study on 16 masonry walls with precast concrete interlocking structural columns. The results showed that the low vertical stresses reduced the lateral capacity of walls, and the fabricated columns could improve the seismic performance of walls. Grouted reinforced masonry walls could also show good seismic performance [28-30]. Concrete blocks are also widely used in recent years, Liu et al. [31] used recycled concrete hollow blocks to construct five masonry shear walls, and the seismic performance of specimens was carried out by cyclic loading tests. The results demonstrated that the aspect ratio, compressive stress, and structural columns would affect the seismic performance of the concrete hollow block walls. The in-plane seismic performance of masonry walls was significantly affected by the walls in the orthogonal direction [32]; therefore, the relationship between the longitudinal and lateral walls should not be ignored.

Masonry walls are also usually used as infill walls in RC frames. De Risi et al. [33] summarized the in-plane behavior and damage assessment of masonry infill walls in RC frames. Through the comparison of numerical simulation and experimental results, the drift-based fragility functions were considered as a key point to estimate the damage of the infill walls. Furtado et al. [34] established a macromodel to account for the out-of-plane behavior infill masonry (IM) walls, which included the corresponding interaction between in-plane and out-of-plane. In another paper of Furtado et al. [35], different strengthening techniques were adopted to investigate the seismic performance of soft story as well as the influence of the presence of IM walls on the structural behavior. The results indicated that the addition of steel braces with an energy dissipation device was the most efficient strengthening technique. Compared with the failure mode of bearing masonry walls in masonry structures, the crack patterns of infill masonry walls in RC frames were also horizontal straight shape or " $X$ " shape $[36,37]$.

In summary, the in-plane performance of masonry walls could be used to study the mechanical properties of masonry structures. Considering the lack of knowledge on the fired shale hollow blocks, especially the feasibility of application in engineering, the cyclic loading tests could be conducted to investigate the seismic performance of fired shale hollow block walls.

In this paper, a new type of fired shale hollow block is used to construct masonry walls. The compressive strength of this type of block has been obtained [38]. In order to investigate the influence of aspect ratio, vertical compressive stress, and the structural columns on the seismic performance of masonry walls, six specimens are fabricated: two bare walls with different aspect ratios and four reinforced walls with different aspect ratios and vertical compressive stress. The seismic behavior of the specimens, such as failure modes, hysteresis curves, envelope curves, ductility, stiffness degradation characteristics, and energy dissipation capacity, is discussed.

\section{Experimental Program}

2.1. Materials. The new type of fired shale hollow block, with a void ratio of approximately $50 \%$, was provided by Chongqing Jukang Building Materials Co., Ltd (Figure 1), and the dimension of the block was $240 \mathrm{~mm} \times 200 \mathrm{~mm} \times 190 \mathrm{~mm}$. In order to ensure the bonding effect between the blocks, ordinary cement mortar with a standard $28 \mathrm{~d}$ strength grade of $5.34 \mathrm{MPa}$ was used as the binder, in which the $28 \mathrm{~d}$ strength grade of cement was $32.5 \mathrm{MPa}$, and the mixture proportion of mortar is given in Table 1. To reduce the variables during the test, the properties of the mortar used in all the specimens were the same. The yielding strength of longitudinal rebars and stirrups was $335 \mathrm{MPa}$ and $235 \mathrm{MPa}$, respectively. 


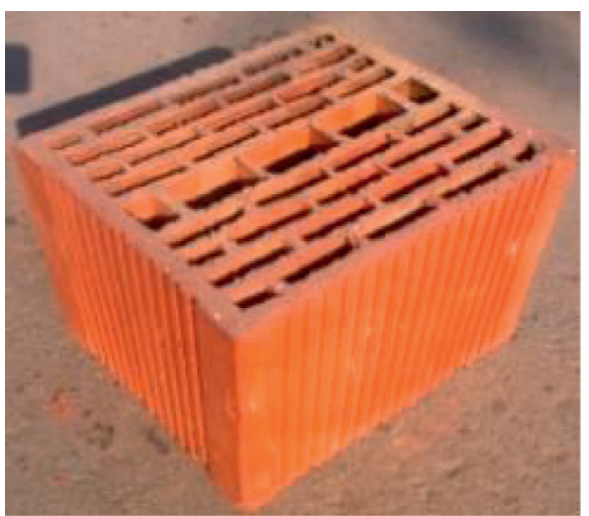

(a)

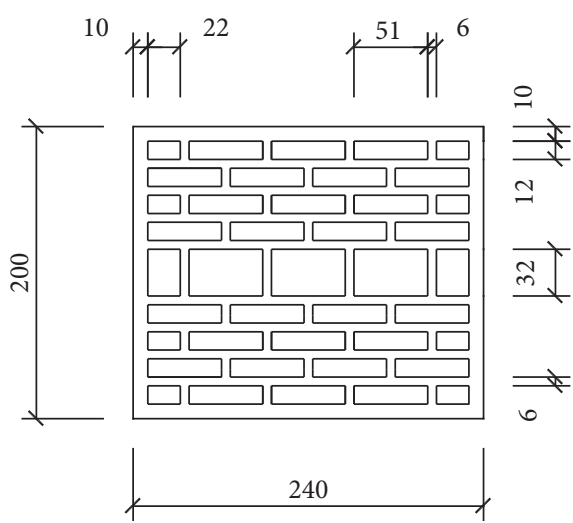

(b)

Figure 1: Dimensions of fired shale hollow block.

TABLE 1: Composition of mortar.

\begin{tabular}{lcc}
\hline Cement $\left(\mathrm{kg} / \mathrm{m}^{3}\right)$ & Sand $\left(\mathrm{kg} / \mathrm{m}^{3}\right)$ & Water $\left(\mathrm{kg} / \mathrm{m}^{3}\right)$ \\
\hline 210 & 1450 & 330 \\
\hline
\end{tabular}

The failure phenomena of fired shale hollow block under compressive stress is given in Figure 2, through which it could be obtained that splitting cracks appeared in the corners when the block was broken. The compressive test results of fired shale hollow block and mortar are shown in Tables 2 and 3. For fired shale hollow block, the value of the coefficient of variation was $15.55 \%$, which met the requirement of Chinese standard GB/T 13545-2014 (21\%) [21], while for mortar, the difference between the maximum value or minimum value and the median value of compressive strength should not be larger than 15\%; otherwise, the maximum and minimum values should be deleted, and the average value of residual data was used to represent the compressive strength of mortar [39]. Therefore, the compressive strength of fired shale hollow block and mortar was $5.55 \mathrm{MPa}$ and $5.34 \mathrm{MPa}$, respectively.

2.2. Design of Specimens. Based on Chinese standards GB 50003-2011 [40] and GB 50011-2010 [41], the fired shale hollow blocks could not be used as structural elements, and the height and number of floors of masonry structures built with fired shale hollow block were different from those of the masonry structures built with fired common bricks, as given in Table 4.

In this paper, the seismic performance of six single-story fired shale hollow block walls, subjected to in-plane cyclic lateral force, was studied. Four specimens (W3-W6) were reinforced by structural columns, while the other two (W1 and W2) had no structural columns. W1 and W2 were tested to study the influence of aspect ratio on the seismic capacity, while the cyclic loading tests of W3-W6 were conducted to obtain the influence of structural columns, aspect ratio, and vertical compressive stress on the seismic performance. The bottom beam could fix the specimens on the lab floor, and the ring beam would help make the compressive stress distribution more uniform. Based on an ordinary 3-story residential building, the height of the specimens was established as $3.05 \mathrm{~m}$. Corresponding to the external load and the self-weight on the top floor and bottom floor, the compressive stress applied on the specimens was $0.1 \mathrm{MPa}$ and $0.3 \mathrm{MPa}$, respectively. The compressive stress was kept constant during the test. The dimensions and configuration details of the six specimens are given in Table 5 and Figure 3.

According to Chinese standards [40, 41], the section size of structural columns and ring beams was established as $240 \mathrm{~mm} \times 240 \mathrm{~mm}$ and $240 \mathrm{~mm} \times 250 \mathrm{~mm}$, respectively. The diameters and arrangement of steel bar in the specimens could also meet the requirements of the standards. Additionally, the section size of the bottom beam, which was used to fix the specimens on the lab floor, was $400 \mathrm{~mm} \times 500 \mathrm{~mm}$. Ordinary Portland concrete with $28 \mathrm{~d}$ axial strength of $20.0 \mathrm{MPa}$ was used in the casting of all the reinforced concrete members. The arrangement of steel bar could be seen in Figure 3 .

Figure 4 shows the construction process of the specimens. The specimens were composed of bottom beams, infill walls, structural columns, and ring beams. Before the casting of the bottom beams, the steel bars of structural columns were anchored in the bottom beams. Then the panels were built. Finally, the RC frames were cast. It should be noted that the mortar joints of the masonry walls had a significant influence on the masonry quality, so the fullness degree of mortar joints should not be lower than $80 \%$. The width of the horizontal and vertical mortar joints was required in the range of $8-12 \mathrm{~mm}$.

2.3. Test Setup and Instrumentation. The test setup and instrumentation for measuring deformation are given in Figure 5. To ensure the stability of the bottom of the specimens, the bottom beams were fixed on the floor of the laboratory. The lateral force, exerted by the MTS hydraulic actuator with a capacity of $500 \mathrm{kN}$, was applied on the specimens at a height of $2800 \mathrm{~mm}$. The vertical load was carried out on the specimens by the jack, and a distribution beam was placed between the jack and the ring beam. 


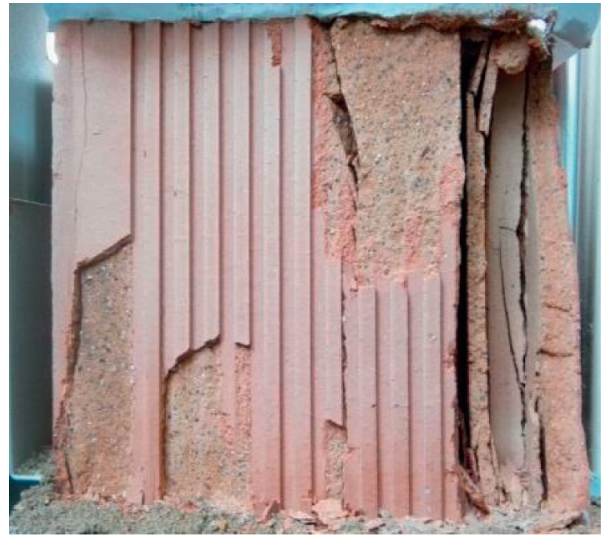

Figure 2: Failure phenomena of fired shale hollow block.

TABLE 2: The compressive strength of fired shale hollow block.

\begin{tabular}{|c|c|c|c|}
\hline No. & Compressive strength $(\mathrm{MPa})$ & Average value (MPa) & Coefficient of variation (\%) \\
\hline CB1 & 6.84 & \multirow{10}{*}{5.55} & \multirow{10}{*}{15.55} \\
\hline $\mathrm{CB} 2$ & 6.08 & & \\
\hline CB3 & 4.69 & & \\
\hline $\mathrm{CB} 4$ & 5.98 & & \\
\hline CB5 & 6.07 & & \\
\hline CB6 & 5.24 & & \\
\hline CB7 & 6.53 & & \\
\hline CB8 & 4.43 & & \\
\hline CB9 & 5.10 & & \\
\hline CB10 & 4.53 & & \\
\hline
\end{tabular}

TABle 3: The compressive strength of mortar.

\begin{tabular}{lcc}
\hline No. & Compressive strength $(\mathrm{MPa})$ & Average value (MPa) \\
\hline CM1 & 4.94 & 5.14 \\
CM2 & 5.19 & 5.34 \\
CM3 & 4.82 & \\
CM4 & 5.59 & \\
CM5 & 5.71 & \\
CM6 & 5.14 & \\
\hline
\end{tabular}

TABLE 4: Floor number and height limit of masonry structures.

\begin{tabular}{|c|c|c|c|c|c|c|c|c|c|}
\hline \multirow{3}{*}{ Type of block } & \multirow{3}{*}{$\begin{array}{l}\text { Minimum wall } \\
\text { thickness }(\mathrm{mm})\end{array}$} & \multicolumn{8}{|c|}{ Basic ground motion acceleration } \\
\hline & & \multicolumn{2}{|c|}{$0.05 \mathrm{~g}$} & \multicolumn{2}{|c|}{$0.15 \mathrm{~g}$} & \multicolumn{2}{|c|}{$0.30 \mathrm{~g}$} & \multicolumn{2}{|c|}{$0.40 \mathrm{~g}$} \\
\hline & & $\begin{array}{l}\text { Height } \\
\text { (m) }\end{array}$ & $\begin{array}{c}\text { Floor } \\
\text { number }\end{array}$ & $\begin{array}{l}\text { Height } \\
\text { (m) }\end{array}$ & $\begin{array}{c}\text { Floor } \\
\text { number }\end{array}$ & $\begin{array}{l}\text { Height } \\
\text { (m) }\end{array}$ & $\begin{array}{c}\text { Floor } \\
\text { number }\end{array}$ & $\begin{array}{l}\text { Height } \\
\text { (m) }\end{array}$ & $\begin{array}{l}\text { Floor } \\
\text { number }\end{array}$ \\
\hline $\begin{array}{l}\text { Fired common } \\
\text { brick }\end{array}$ & 240 & 21 & 7 & 21 & 7 & 15 & 5 & 12 & 4 \\
\hline $\begin{array}{l}\text { Fired shale } \\
\text { hollow block }\end{array}$ & 240 & 21 & 7 & 18 & 6 & 15 & 5 & 9 & 3 \\
\hline
\end{tabular}

Additionally, in order to prevent the test setup from affecting the horizontal displacement of the specimens, rollers were placed between the jack and door-type steel support structure. Moreover, two groups of linear variable differential transformers (LVDTs) were used to measure the displacements of the specimens. The first group contained two horizontal LVDTs, which were placed in the middle of the ring beam and the bottom beam to measure the horizontal displacement of the specimens. The second group consisted of two LVDTs, which were arranged at both ends of the bottom beam to monitor the lift of the bottom beam. Finally, the occurrence, 
TABLE 5: Design of fired shale hollow block masonry walls.

\begin{tabular}{|c|c|c|c|c|c|c|}
\hline No. & W1 & W2 & W3 & W4 & W5 & W6 \\
\hline Width (mm) & 2300 & 3350 & 2780 & 2780 & 3830 & 3830 \\
\hline Height (mm) & 3050 & 3050 & 3050 & 3050 & 3050 & 3050 \\
\hline Aspect ratio & 1.326 & 0.910 & 1.097 & 1.097 & 0.796 & 0.796 \\
\hline Vertical compressive stress (MPa) & 0.3 & 0.3 & 0.1 & 0.3 & 0.1 & 0.3 \\
\hline Structural columns & - & - & $\sqrt{ }$ & $\sqrt{ }$ & $\sqrt{ }$ & $\sqrt{ }$ \\
\hline
\end{tabular}
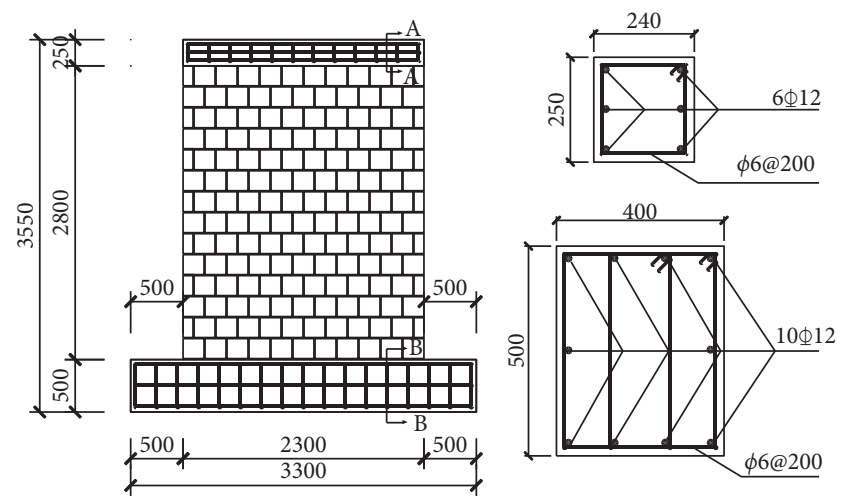

(a)

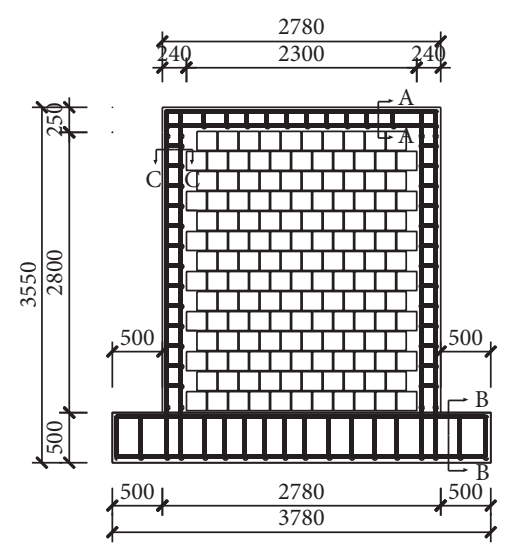

(c)

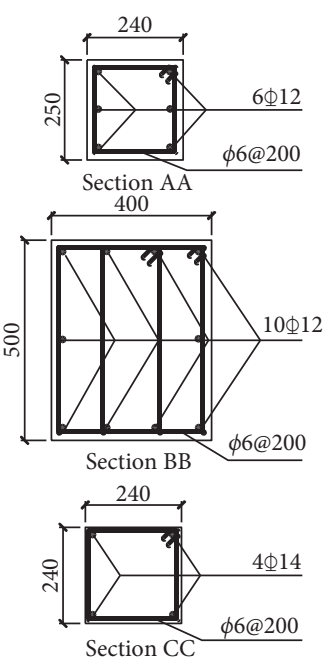

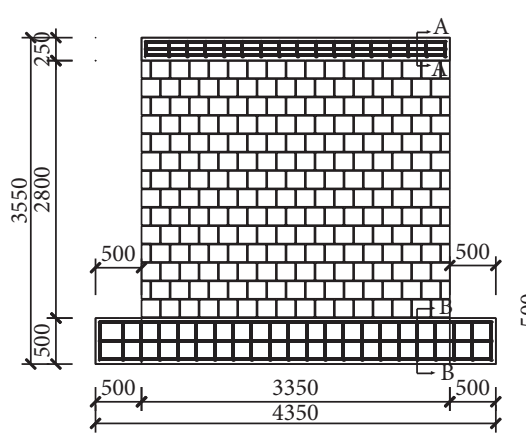

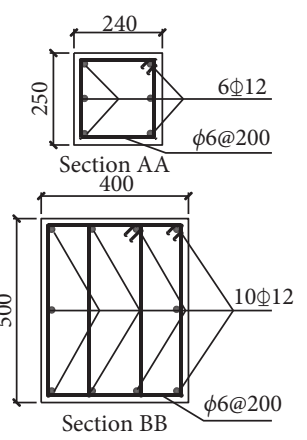

(b)
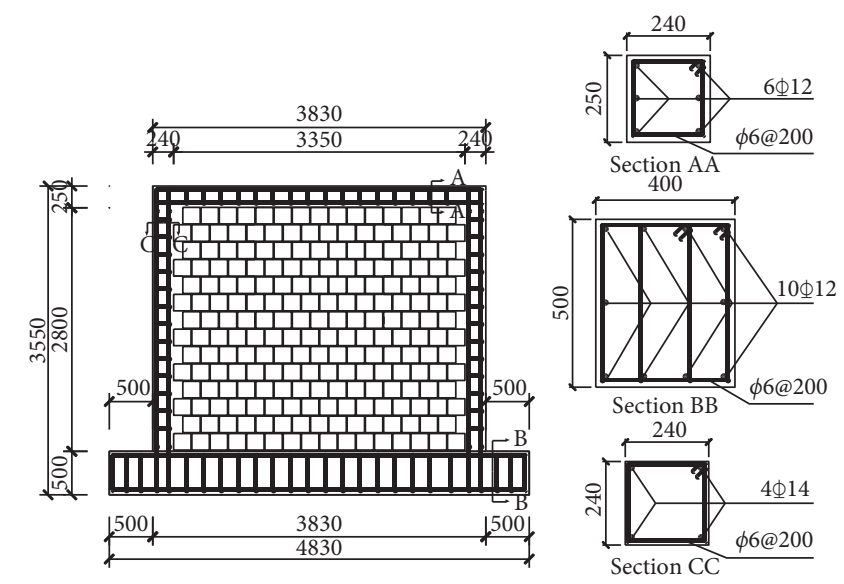

(d)

Figure 3: Design details of specimens. (a) W1; (b) W2; (c) W3 and W4; (d) W5 and W6.

development, and width of the cracks were recorded at every loading process.

2.4. Test Procedure. The lateral loading procedure consisted of two steps (Figure 6): load-controlled step and displacement-controlled step. Before applying the lateral load, the specimens were subjected to a vertical precompression load, which was kept continuous during the loading process. During the load-controlled step, the loading process was controlled by the lateral load with an increment, and the loading cycle was repeated once until the cracks of walls occurred continuously, then the loadcontrolled step was changed to displacement-controlled step, and three cycles were completed at each displacement magnitude until the wall was broken. To obtain the seismic performance of the walls and guarantee the safety of personnel, the load process stopped when the lateral resistance of the specimens decreased to approximately $85 \%$ of the maximum load (W3-W6), or the cracks at the bottom of the wall linked together along the mortar joints (W1 and W2). 


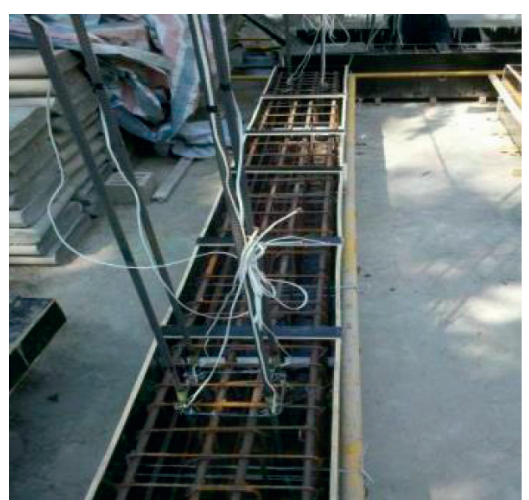

(a)

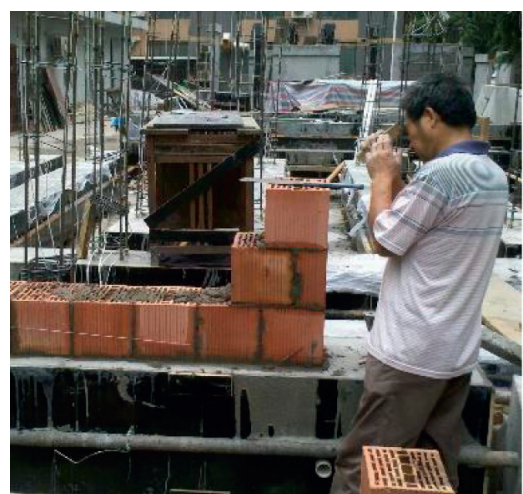

(b)

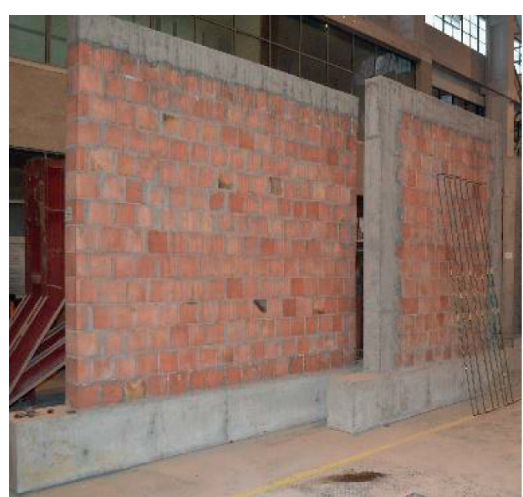

(c)

Figure 4: Process of construction: (a) bottom beam; (b) masonry walls; (c) specimens.

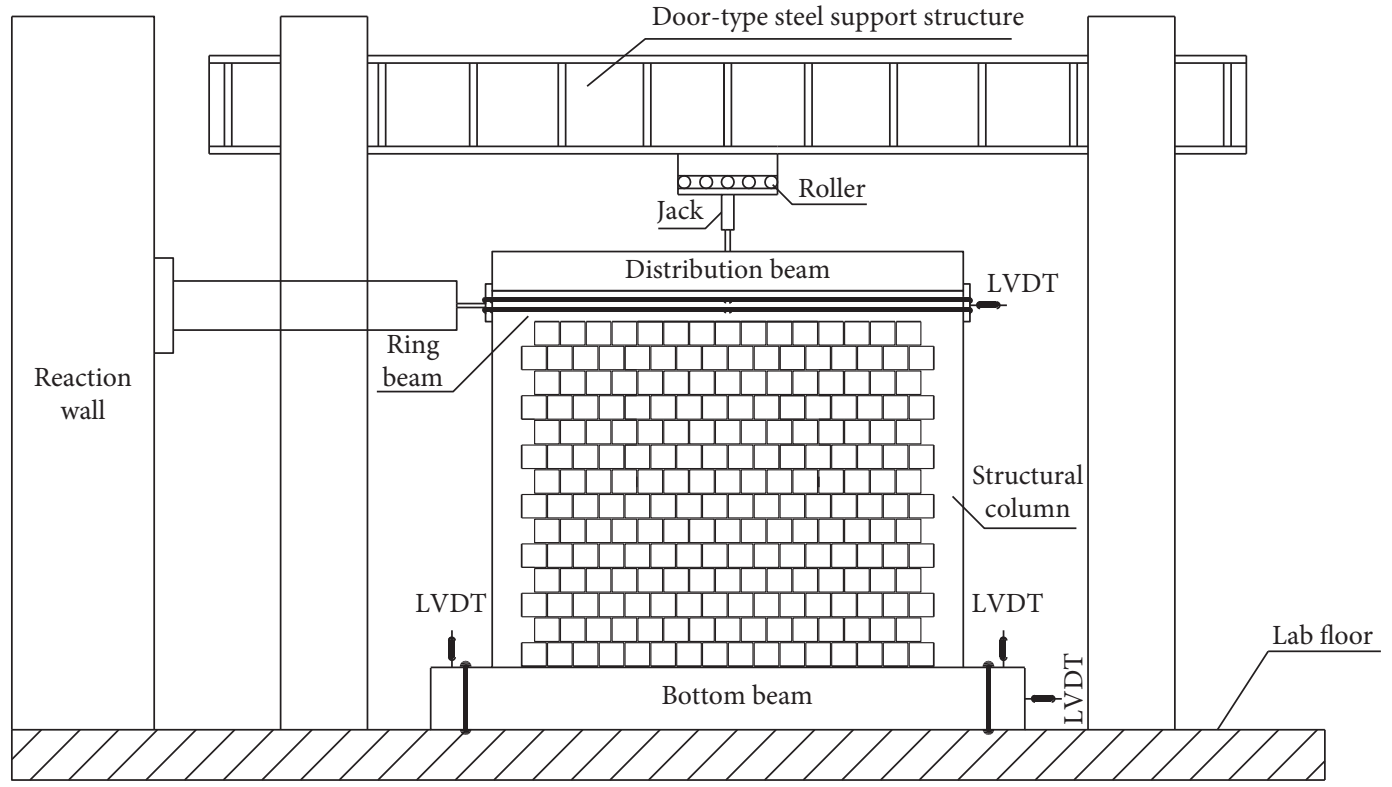

Figure 5: Test setup.

\section{Test Results}

3.1. Experimental Observation and Failure Pattern. Figure 7 shows the failure patterns of six specimens. The specimens W3-W6 experienced three phases, such as cracking state, maximum state, and ultimate state during the loading process, indicating that the failure process of the specimens was continuous without sudden failure, while the specimens W1 and W2 (bare walls) were destroyed once reached the maximum lateral load, and the cracks developed rapidly after they appeared. Through the comparison of the experimental observations of all the specimens, it can be concluded that the ductility and bearing capacity of the specimens could be improved due to the constraint of the reinforced concrete members (structural columns and ring beams). The analysis of the experimental observations and failure patterns of the specimens is summarized as follows:
(1) For specimen $\mathrm{W} 1$, in the initial stage of loading, cracks firstly occurred on the mortar joint of the wall root between the masonry wall and bottom beam. Due to the reason that the shear load had not reached the cracking load in the diagonal direction, there were no visible cracks occurred in the diagonal direction. With the increase of lateral load, the cracks at the wall root developed upwards to the mortar joint between the first and second layer blocks at the bottom of the infill wall, and the subsequent cracks propagated horizontally along this mortar joint. When the lateral load reached the maximum value, the horizontal cracks linked together, and the fired shale hollow blocks at the wall root were broken. The failure process of the specimen obviously showed the characteristics of bending failure. It could also be observed that there was a vertical crack appeared in 


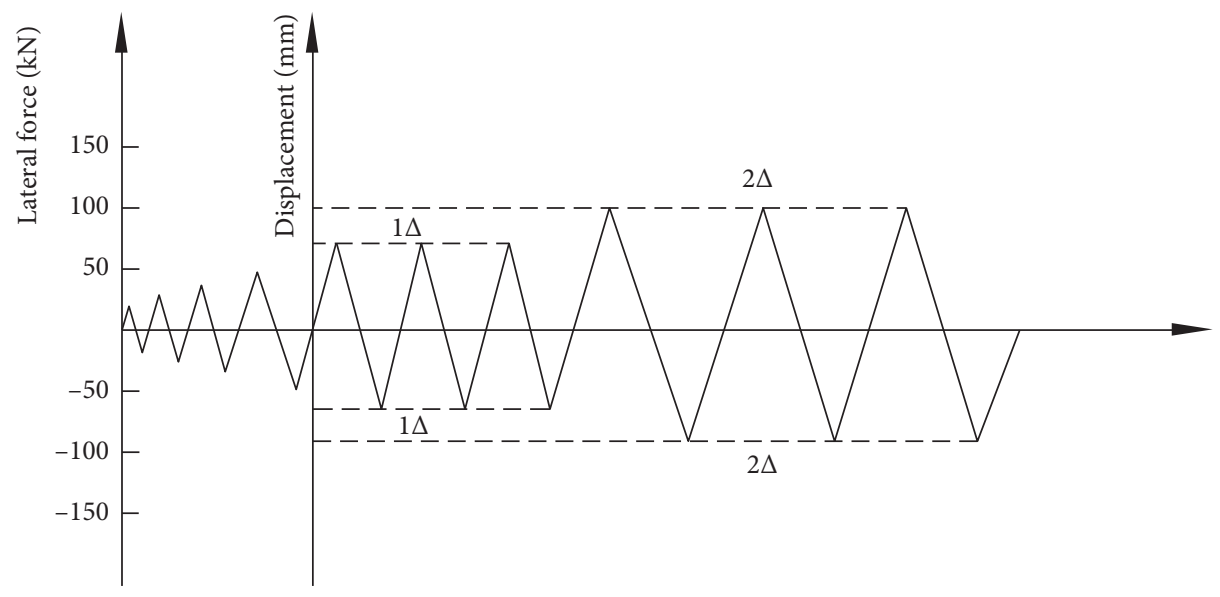

Figure 6: Lateral loading process.

the middle of the wall when the specimen was failed, the reason for this observation was probably due to the concentrated force produced by the jack.

(2) Although the value of aspect ratio was smaller than that of W1, specimen W2 was still obviously affected by the bending effect and shear effect under lateral load, and the failure pattern of W2 was similar to that of W1.

(3) For specimens W3-W6, in the initial stage of loading, cracks firstly appeared at the both sides of the wall root, and there were no cracks occurred in the structural columns at this time. With the increase of lateral load, the horizontal cracks began to appear at the bottom of the structural columns, and the cracks in the masonry wall developed in the diagonal direction. As the lateral load further increased, the width of the cracks in the masonry walls increased gradually, and so did the number of the cracks in the structural columns. The " $X$ " shape cracks were formed at this stage. When the displacement of the specimens reached the maximum value, the spalling of broken blocks was observed in the middle and upper part of the masonry walls. It could also be obtained that the cracks in the masonry walls were either stepped cracks or diagonal cracks. The stepped cracks were due to the fact that the shear stress exceeded the bond strength between the blocks and mortar, while the appearance of diagonal cracks was caused by the reason that the compressive stress was larger than the tensile strength of the block.

\subsection{Experimental Force-Displacement Response}

3.2.1. Hysteretic Behavior. Figure 8 presents the load-displacement response of all the specimens under cyclic loading. It should be noted that during the loading process of $\mathrm{W} 1$ and W2, extra load was applied after the lateral load reached the maximum value so as to obtain more failure modes (Figures $8(\mathrm{a})$ and $8(\mathrm{~b})$ ). Therefore, the analysis of this paper took the test results before the cracks linked together as the research object [32].

Figures 8 (a) and 8 (b) present that, in the initial stage of loading, the hysteresis curves of $\mathrm{W} 1$ and $\mathrm{W} 2$ were linear, indicating that the specimens were in the elastic stage. When the specimens entered the elastic-plastic stage, a large angle of rotation in the upper part was observed due to the flexural effect. However, for W2, the shape of the hysteresis curve was "shuttle" shape, which indicated that the specimen was mainly affected by the shear effect.

As shown in Figures 8(c)-8(e), with the constraint of structural columns and ring beams, the shapes of hysteresis curves were basically "shuttle" shape, indicating that the constraint members could improve the mechanical performances of the specimens. Moreover, in the initial elastic stage, the relationship of lateral load and displacement was still linear, and the area of hysteresis loops was small, while in the elastic-plastic stage, the area of hysteresis loop increased significantly.

3.2.2. Characteristic Load and Displacement. The hysteretic curve could be divided into three stages: crack state, maximum state, and ultimate state. The crack state indicates that the cracks occurred continuously in the specimens, the max state represents that the lateral resistance of the specimens reached the maximum value, and the ultimate state is the test stop state that the lateral resistance of the specimens is reduced by approximately $15 \%$. The measured characteristic load and displacement of three stages are given in Table 6.

As can be seen in Table 6, with the constraint of structural columns, the cracking load and cracking displacement decreased. The maximum loads of W2, W5, and W6 were $83.57 \%, 32.74 \%$, and $42.20 \%$ higher than those of specimens W1, W3, and W4, respectively, indicating that the smaller aspect ratio could improve the bearing capacity of the specimens. Compared with W1 and W2, the maximum loads of W4 and W6 increased by $150.37 \%$ and $93.93 \%$, respectively, indicating that the structural columns could effectively improve the bearing capacity of the specimens. Moreover, it could also be found that the maximum 


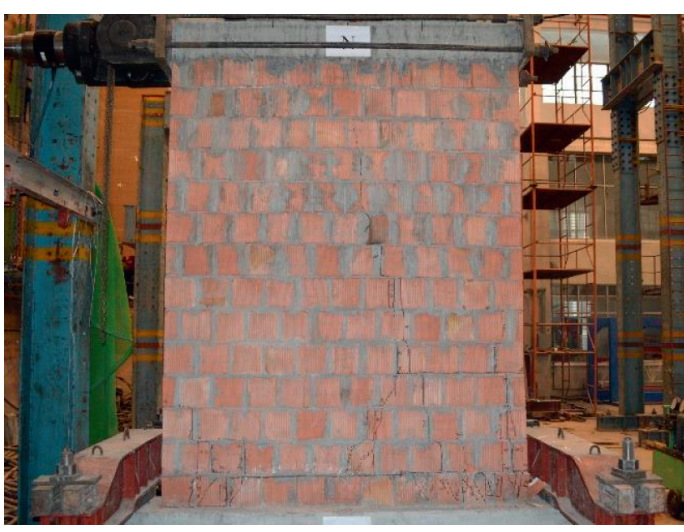

(a)

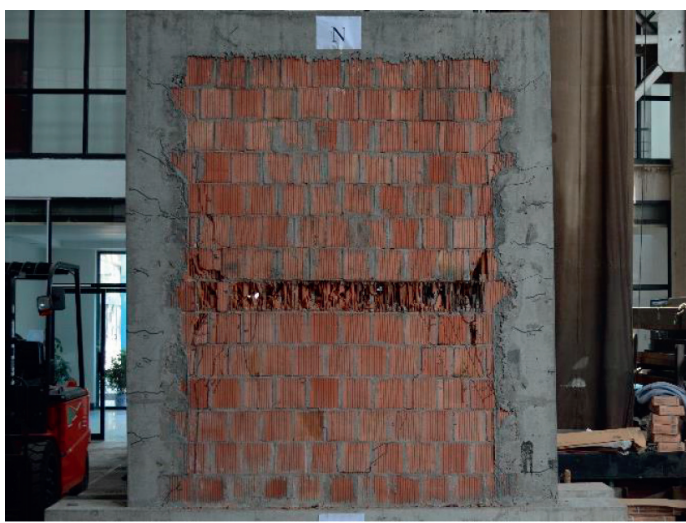

(c)

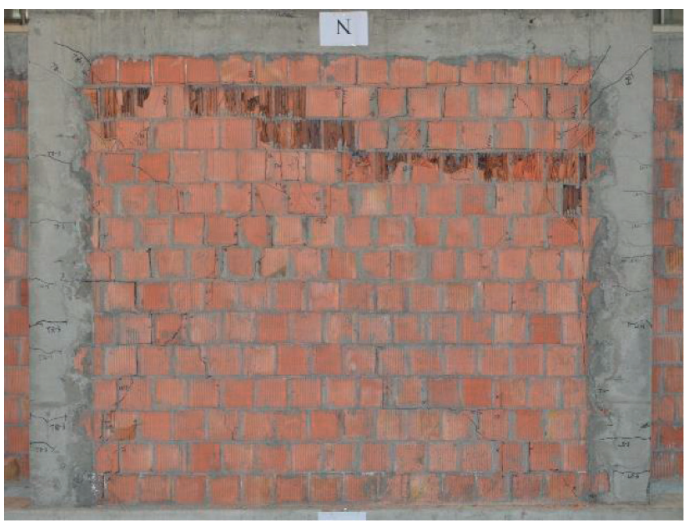

(e)

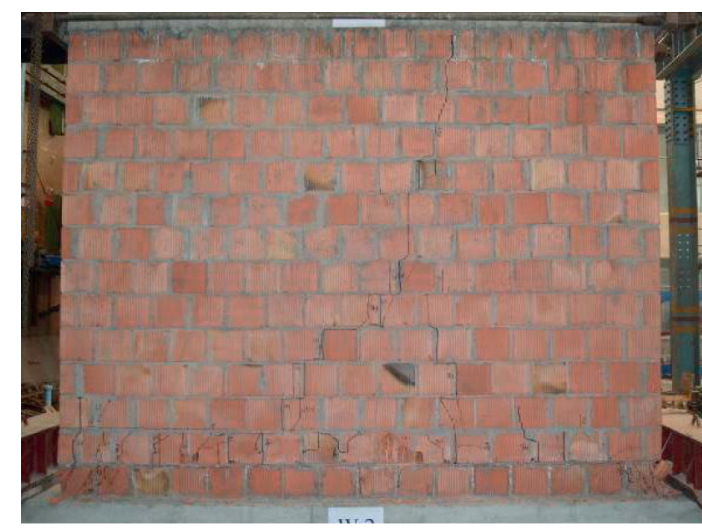

(b)

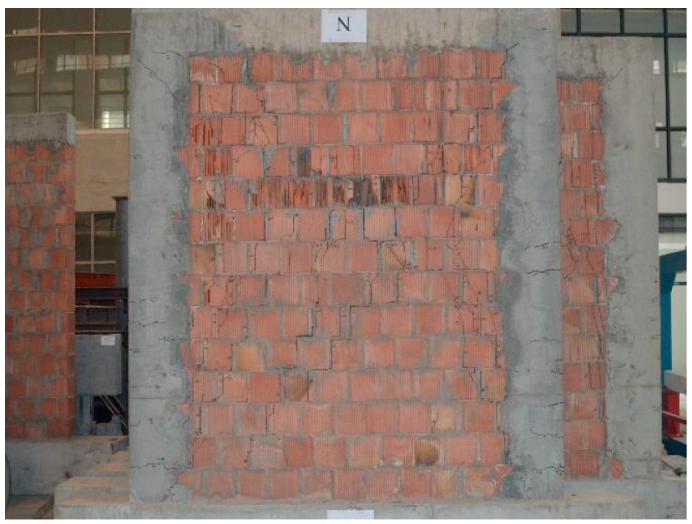

(d)

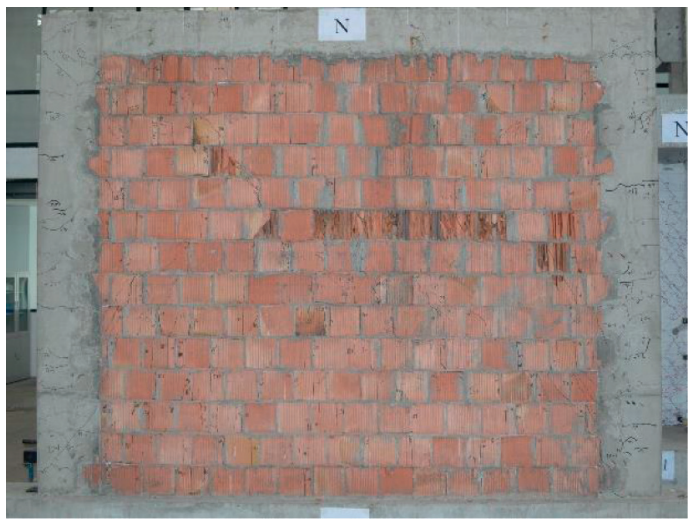

(f)

FIgURe 7: Failure mode of the specimens: (a) W1; (b) W2; (c) W3; (d) W4; (e) W5; (f) W6.

displacement of W4 and W6 was $146.78 \%$ and $35.89 \%$ higher than that of $\mathrm{W} 1$ and $\mathrm{W} 2$, respectively, indicating that the structural columns could significantly improve the deformation capacity of the walls.

\section{Discussion of Test Results}

4.1. Envelope Curves. The envelope curve, which is commonly used to analyze the seismic performance of the specimens (characteristic load and ductility), is obtained by the connection of maximum load of each hysteretic loop.
Figure 9 presents the envelope curves of all specimens. In the initial stage of loading, the envelope curves of $\mathrm{W} 1$ and W2 were straight line, indicating that the specimens were in the elastic state. After the cracks occurred in the wall, the specimens entered the elastic-plastic state, and the envelope curves became nonlinear. Compared with W2, the specimen W1 had a smoother envelope curve and a smaller maximum load. This might be because the aspect ratio of $\mathrm{W} 1$ was larger than that of the specimen W2, resulting in a more obvious flexural effect.

It could be found that with the constraints of structural columns and beams, the specimens W3-W6 still kept the 


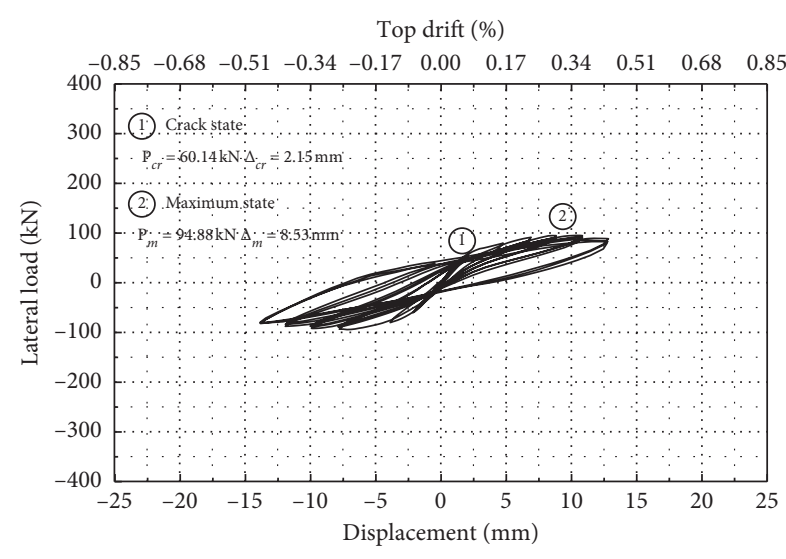

(a)

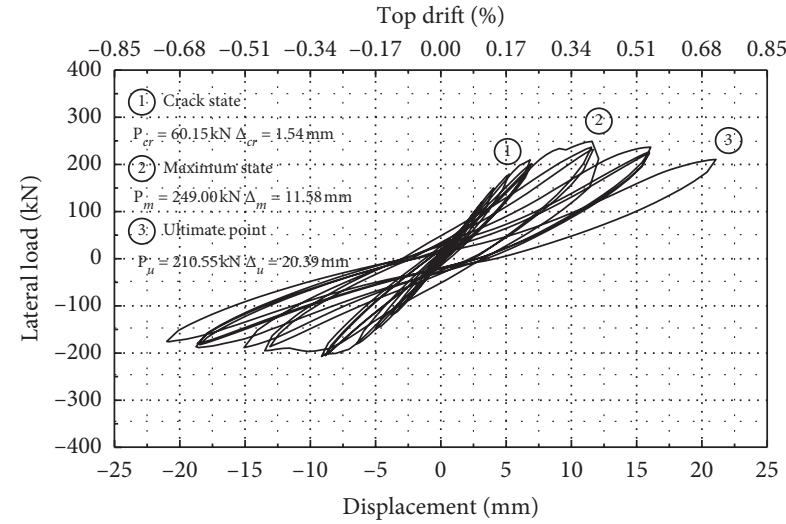

(c)

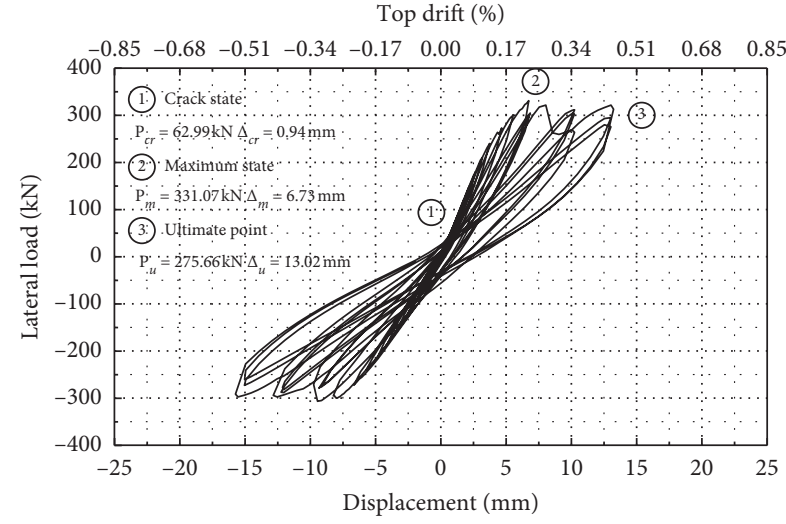

(e)

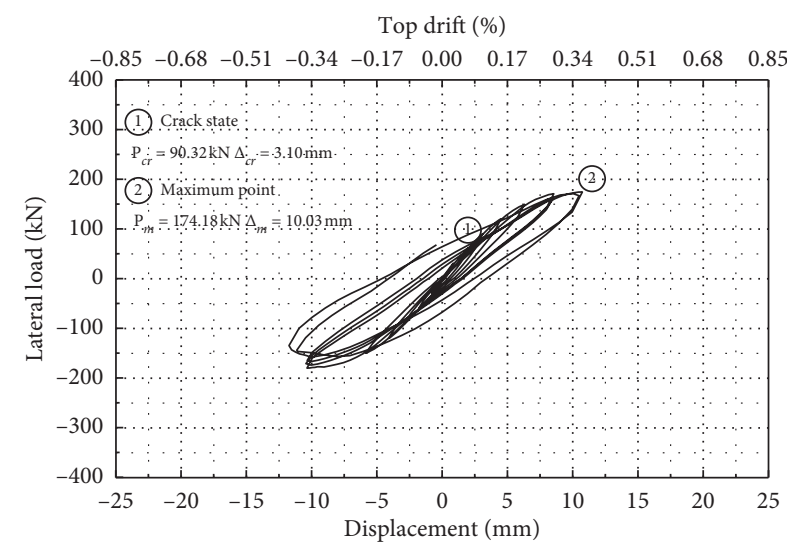

(b)

Top drift (\%)

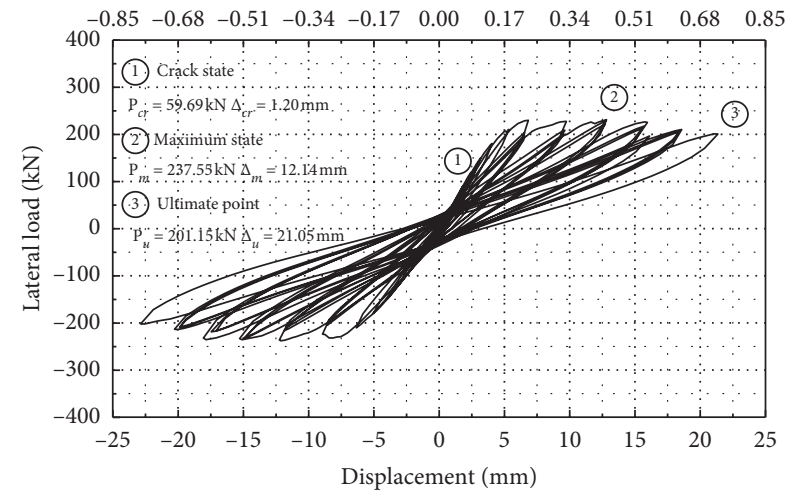

(d)

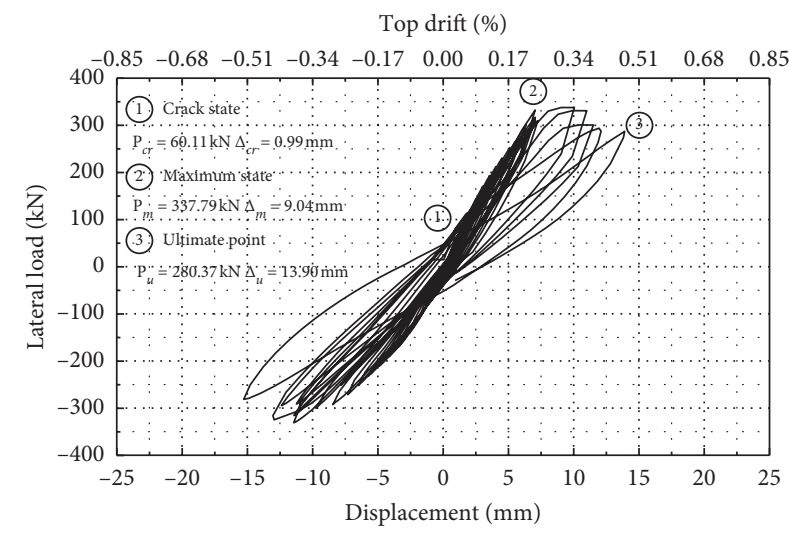

(f)

FIgURE 8: Hysteretic curves of specimens: (a) W1; (b) W2; (c) W3; (d) W4; (e) W5; (f) W6.

TABLE 6: Characteristic load and displacement.

\begin{tabular}{lccccccc}
\hline No. & W1 & W2 & W3 & W4 & W5 & W6 & Unit \\
\hline$P_{c r}$ & 60.14 & 90.32 & 60.15 & 59.49 & 62.99 & 60.11 & $\mathrm{kN}$ \\
$\Delta_{c r}$ & 2.15 & 3.10 & 1.54 & 1.20 & 0.94 & 0.99 & $\mathrm{~mm}$ \\
$P_{m}$ & 94.88 & 174.18 & 249.00 & 237.55 & 331.07 & 337.79 & $\mathrm{kN}$ \\
$\Delta_{\mathrm{m}}$ & 8.53 & 10.03 & 11.58 & 12.14 & 6.73 & 9.04 & $\mathrm{~mm}$ \\
$P_{u}$ & - & - & 210.55 & 201.15 & 275.66 & 280.37 & $\mathrm{kN}$ \\
$\Delta_{u}$ & - & - & 20.39 & 21.05 & 13.02 & 13.90 & $\mathrm{~mm}$ \\
\hline
\end{tabular}

$P_{c r}$ is the cracking load; $\Delta_{c r}$ is the cracking displacement; $P_{m}$ is the maximum load; $\Delta_{\mathrm{m}}$ is the displacement corresponding to the maximum load; $P_{u}$ is the ultimate load; $\Delta_{u}$ is the ultimate displacement. lateral resistance even if the specimens had reached the maximum load, and the bearing capacity and deformation property were obviously higher than those of W1 and W2. In comparison with W3 and W4, W5 and W6 had larger maximum loads and smaller ultimate displacements, indicating that the increase of aspect ratio could reduce the maximum load and increase the ductility. Considering the influence of compressive stress and structural columns, it could be observed that these two factors could improve the initial stiffness of the specimens in the elastic stage. 


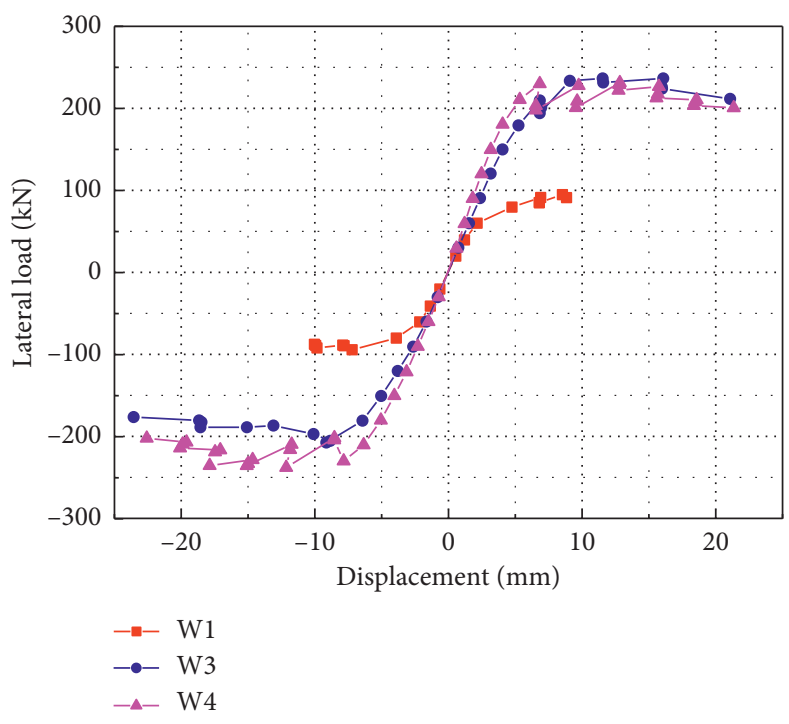

(a)

FIgURE 9: Envelope curves of specimens: (a) W1, W3, and W4; (b) W2, W5, and W6.

(b)
4.2. Ductility. The ductility coefficient and shift angle, which are related to the failure modes of the specimens, are usually used to assess the deformation capacity of the walls. Before the calculation of the ductility coefficient, two characteristic displacements must be identified: yield displacement and ultimate displacement. The ultimate displacement is the displacement corresponding to approximately $85 \%$ of the maximum load. However, due to the complexity of the failure pattern and difference of calculation method, the yield displacement is not easy to determine. In this paper, energy equivalent method [42] is used to obtain the yield displacement, as shown in Figure 10.

The calculation of ductility coefficient $(\mu)$ and shift angle $(\theta)$ is expressed as follows:

$$
\begin{gathered}
\mu=\frac{\Delta_{u}}{\Delta_{y}}, \\
\theta=\frac{\Delta_{u}}{H} .
\end{gathered}
$$

where $\Delta_{u}$ is the ultimate displacement, $\Delta_{y}$ is the yield displacement, and $H$ is the height of masonry walls.

Table 7 presents the calculation results of the ductility coefficient and shift angle of the specimens. The ductility coefficient of $\mathrm{W} 1$ and $\mathrm{W} 2$ was within a range of values between 1.87 and 1.96, and compared with W3 W6, the ductility coefficient of $\mathrm{W} 1$ and $\mathrm{W} 2$ was smaller. As a result of smaller yield displacement, although the ultimate displacement of W5 and W6 was smaller than that of W3 and W4, the ductility coefficient of W5 and W6 basically had no change.

According to Chinese standard GB 50003-2011 [39], the ductility coefficient of specimens should not be less than 3.0, without the constraints of structural columns and ring beams, and W1 and W2 could not meet the specification requirements, indicating that only the reinforced specimens

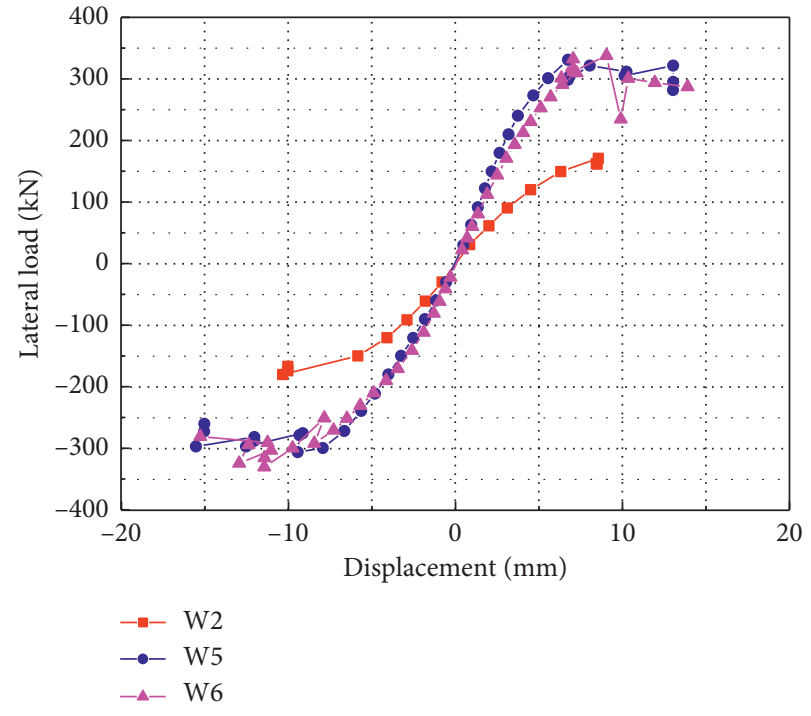

could be used in engineering structures. It could also be observed that the compressive stress could increase the shift angle of the specimens. Similar conclusions were also provided by Liu et al. [31].

4.3. Stiffness Degradation. Stiffness is an important index to reflect the seismic performance of the specimens. As we all know, the stiffness of the specimens would decrease with the increase of damage degree. In order to obtain the stiffness degradation of the specimens, the stiffness degradation factor $K_{i}$ is adopted in this paper, which can be calculated by the following equationfd3:

$$
K_{i}=\frac{\left|P_{\max , i}\right|+\left|-P_{\min , i}\right|}{\left|\Delta_{\max , i}\right|+\left|-\Delta_{\min , i}\right|},
$$

where $P_{\max , i}$ and $-P_{\min , i}$ are maximum load at the $i$ cycle and $\Delta_{\max , i}$ and $-\Delta_{\min , i}$ are the displacement corresponding to the maximum load, respectively. The initial stiffness was the calculation result of equation (2) in the first cycle. The curves of stiffness degradation are presented in Figure 11.

As shown in Figure 11(a), the stiffness of W1 and W2 decreased with the increase of the displacement. Comparing with W1, the stiffness degradation curve of W2 was higher, indicating that the stiffness decreased with the increase of aspect ratio. After cracks occurred in the specimens, the stiffness of W1 dropped faster than W2, which may be due to the reason that the flexural effect led to faster development of cracks in the specimens. In addition, the stiffness degradation curves of W2 were smoother than those of W1, showing that the aspect ratio could improve the degradation rate of the specimens.

It could be observed from Figure 11(b) that the stiffness degradation trend of specimens W3-W6 was consistent. The stiffness in the early stage of loading dropped quickly, while the stiffness degradation curves tended to be smoother at the 


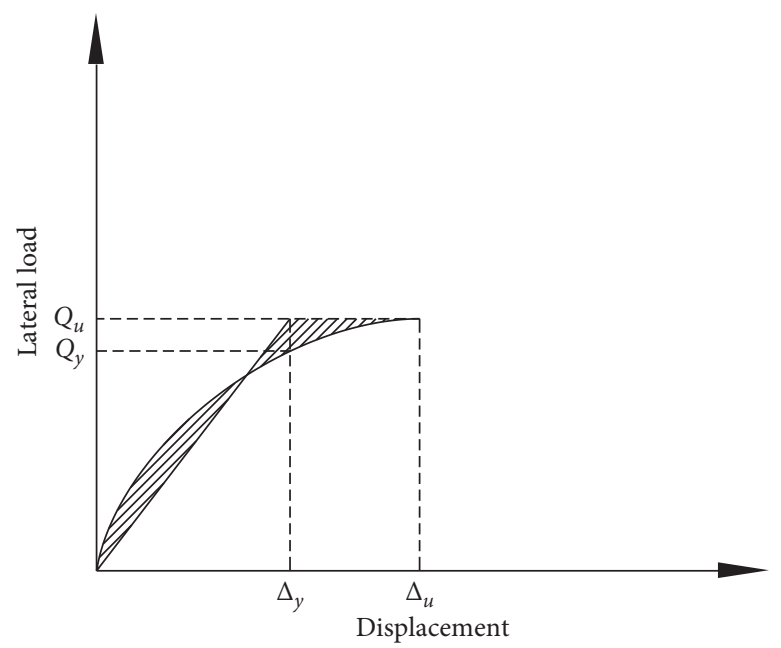

FIGURE 10: Determination of yielding state.

TABLe 7: Ductility coefficient and shift angle of specimens.

\begin{tabular}{lccccccc}
\hline No. & W1 & W2 & W3 & W4 & W5 & W6 & Unit \\
\hline$\Delta_{y}$ & 4.57 & 5.12 & 3.84 & 3.53 & 2.33 & 2.50 & $\mathrm{~mm}$ \\
$\Delta_{u}$ & 8.53 & 10.03 & 20.39 & 21.05 & 13.02 & 13.90 & $\mathrm{~mm}$ \\
$H$ & 2800 & 2800 & 2800 & 2800 & 2800 & 2800 & $\mathrm{~mm}$ \\
$\mu$ & 1.87 & 1.96 & 5.31 & 5.96 & 5.59 & 5.56 & - \\
$\theta$ & 0.0030 & 0.0036 & 0.0073 & 0.0075 & 0.0047 & 0.0050 & - \\
\hline
\end{tabular}

end of the loading process. The stiffness degradation curves of W5 and W6 were higher than those of W1 and W2, which was consistent with the comparison of $\mathrm{W} 1$ and $\mathrm{W} 2$. The stiffness of W3 and W5 was lower than that of W4 and W6, respectively, which stated that the stiffness of the specimens increased with the increase of compressive stress. Besides, the structural columns could improve the stiffness of the specimens through the comparison of Figures 11(a) and 11(b).

Table 8 gives the secant stiffness at different characteristic states. It could be concluded that the secant stiffness at different characteristic states increased with the decrease of aspect ratio and increase of compressive stress. The stiffness degradation and secant stiffness of the specimens are similar to those provided in the literature [31].

4.4. Energy Dissipation. Besides the stiffness degradation, the energy dissipation, which could be obtained through the calculation of the area surrounded by the hysteretic curve, is another important indicator to measure the seismic performance of the specimens. The energy dissipation of all the specimens is given in Figure 12.

Figure 12(a) shows that the energy dissipation increased with the increase of displacement. The energy dissipation capacity of W2 was better than that of W1, indicating that the aspect ratio would affect the energy dissipation of the specimens, the smaller the aspect ratio, the better the energy dissipation capacity.
Figure 12(b) clearly presents that the constraint of the structural columns and ring beams could improve the energy dissipation capacity of the specimens effectively. The energy dissipation curves of W4 and W6 were higher than those of $\mathrm{W} 3$ and $\mathrm{W} 4$, respectively, indicating that the energy dissipation capacity increased with the increase of compressive stress. In addition, the specimens W5 and W6 with smaller aspect ratios had better energy dissipation capacity than specimens W3 and W4, which coincided with the test results of bare walls (W1 and W2).

Furthermore, equivalent viscous damping coefficient is introduced to simplify the expression of energy dissipation capacity of the specimens. In order to evaluate the seismic performance of the specimens, the maximum state and ultimate state were studied, which were corresponding to the maximum load and ultimate load. The equivalent viscous damping coefficient of maximum state and the ultimate state was represented by $h_{e, m}$ and $h_{e, u}$, respectively, and $h_{e}$ could be calculated as the ratio of the area enclosed by hysteresis loop in one cycle to the energy input by the loading device, as given in the following equation:

$$
h_{e}=\frac{S_{A E C}}{S_{B E D}} .
$$

where $S_{A E C}$ and $S_{B E D}$ are the areas which can be calculated from the position of each point in Figure 13.

Table 9 presents the equivalent viscous damping coefficients of the maximum state and ultimate state of the specimens. Since the cracks had been linked together once the lateral load reached the maximum value, the $h_{e, u}$ of W1 and W2 was ignored.

The equivalent viscous damping coefficient $\left(h_{e, m}\right)$ of W2 was higher than that of $\mathrm{W} 1$, indicating that a smaller aspect ratio could improve the energy dissipation properties of the specimens. The $h_{e, m}$ of W4 and W6 was higher than that of $\mathrm{W} 1$ and W2, respectively, which indicated that the constraint of structural columns could increase the energy 


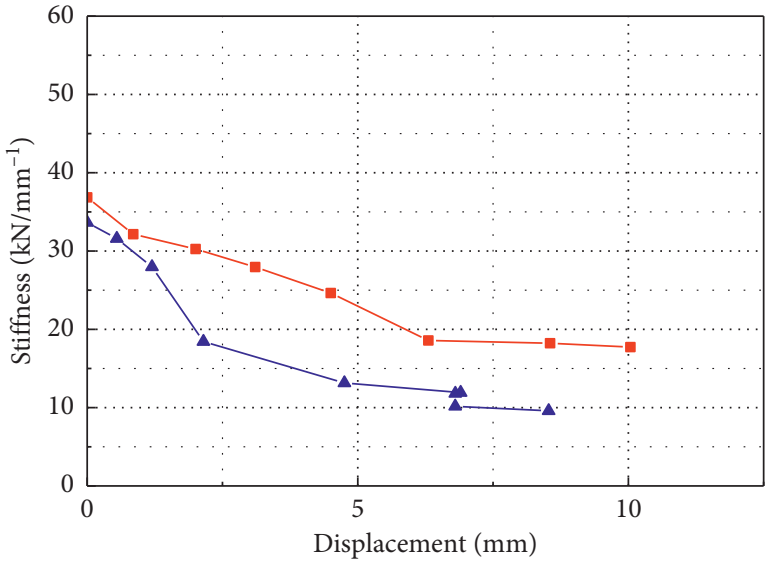

$-\Delta-\mathrm{W} 1$

$--\mathrm{W} 2$

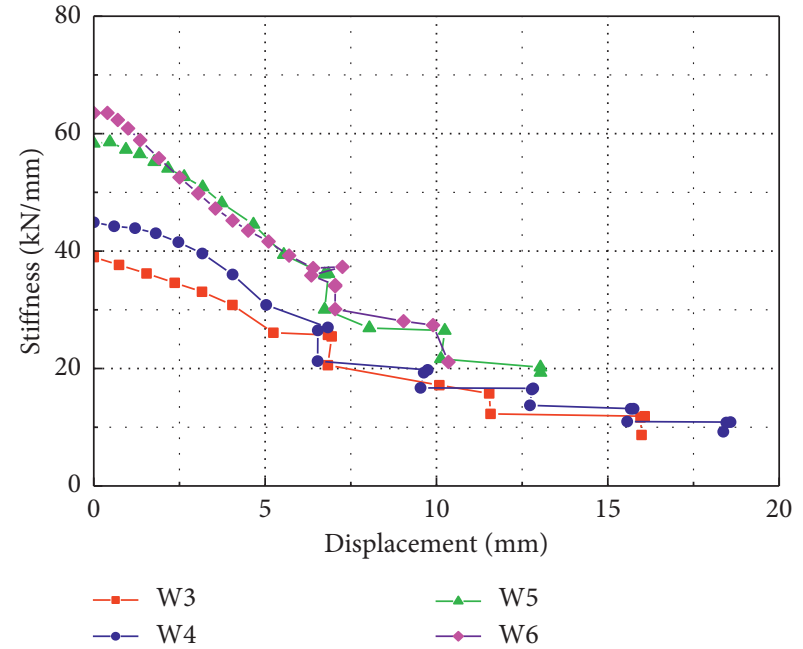

(b)

FIGURE 11: Stiffness degradation of the specimens: (a) W1 and W2; (b) W3-W6.

TABle 8: Secant stiffness at different characteristic states.

\begin{tabular}{lccc}
\hline No. & & Secant stiffness $(\mathrm{kN} / \mathrm{mm})$ & Crack state \\
Initial state & 33.64 & 18.43 & 9.47 \\
W1 & 36.85 & 24.64 & 17.73 \\
W3 & 38.96 & 26.08 & 8.69 \\
W4 & 44.91 & 30.83 & 9.24 \\
W5 & 58.34 & 39.38 & 19.32 \\
W6 & 63.53 & 41.64 & 21.12 \\
\hline
\end{tabular}

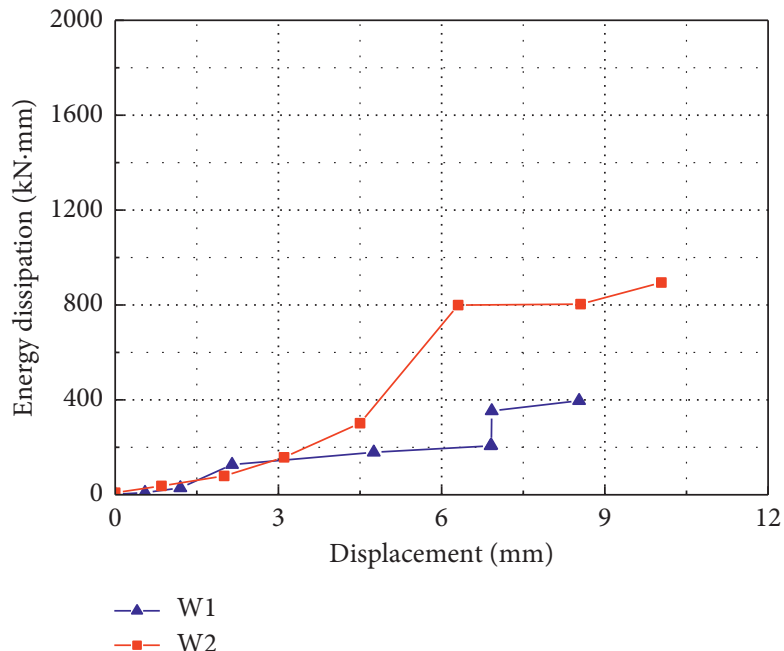

(a)

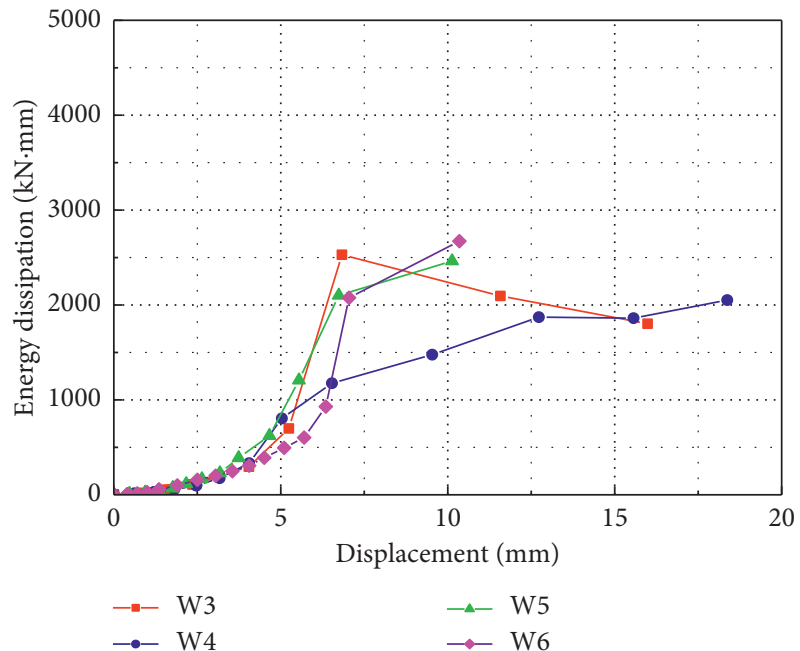

(b)

FIgURE 12: Energy dissipation of the specimens: (a) W1 and W2; (b) W3-W6.

dissipation capacity of the specimens. It could also be obtained that the compressive stress had an adverse effect on the value of $h_{e, u}$ in the maximum state, while in the ultimate state, $h_{e, u}$ increased with the increase of compressive stress, which may be due to the brittleness of the blocks. When the compressive stresses of the specimens with structural columns were small (W3 and W5), the trends of equivalent viscous damping coefficients are slightly different from the conclusions made by Liu et al. [31], and more tests should be carried out to analyze the reason why this happens. 


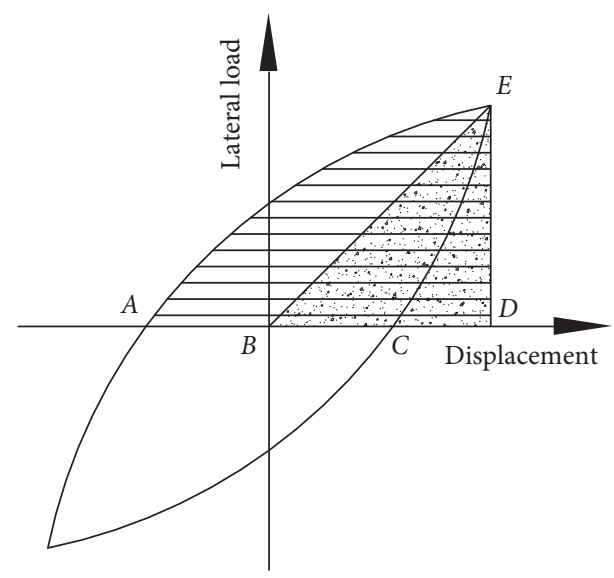

Figure 13: Schematic diagram of energy dissipation.

Table 9: Equivalent viscous damping coefficients of specimens.

\begin{tabular}{lcc}
\hline No. & Maximum state & Ultimate state \\
\hline W1 & 0.0780 & - \\
W2 & 0.0849 & - \\
W3 & 0.1396 & 0.0666 \\
W4 & 0.0834 & 0.1031 \\
W5 & 0.1293 & 0.0849 \\
W6 & 0.0974 & 0.1212 \\
\hline
\end{tabular}

\section{Conclusions}

This paper mainly studied the application feasibility of a new type fired shale hollow block in practical engineering. Cyclic loading tests were carried out to investigate the seismic properties of fired shale hollow block walls. The failure mode of the specimens was presented, and the influence of aspect ratio, compressive stress, and structural columns on the seismic performance of fired shale hollow block walls was analyzed. The conclusions can be drawn as follows:

(1) The specimens exhibit two kinds of failure modes. The cracks of W1 and W2 mainly occur at the bottom of the walls, while the cracks of W3 and W4 occur and develop throughout the wall. The results indicate that the failure modes of bare walls (W1 and W2) and reinforced walls (W3-W6) are flexural failure and shear failure, respectively. Furthermore, the compressive stress has little effect on the failure mode of the specimens.

(2) With the constraint of structural columns and ring beams, the maximum lateral loads and ultimate displacements of the reinforced specimens are significantly larger than those of the bare walls. The structural columns could also improve the stiffness degradation and energy dissipation capacity of fired shale hollow block walls.

(3) With the increase of compressive stress, the ductility, stiffness, and energy dissipation capacity are improved, while the equivalent viscous damping coefficients of specimens W3-W6 at the maximum state decrease due to the brittle properties of the fired shale hollow block.

(4) Without the constraint of structural columns, the ductility of specimen W2, with a small aspect ratio, is smaller than that of the specimen W1. The reason might be that the flexural effect of W1 is more obvious than that of the specimen $\mathrm{W} 2$, resulting in the crushing of fired shale hollow block at the both sides of the wall root. With the decrease of aspect ratio, the stiffness and energy dissipation performances are improved.

In summary, this paper experimentally studied the seismic performance of masonry walls made of a new type of fired shale hollow block. This kind of block could effectively reduce the dead weight of the building walls, thereby reducing the use of steel and concrete, and lower the construction costs. The high void ratio of this type of block could also ensure the thermal insulation performance of buildings. However, the application of fired shale hollow blocks still has many problems, such as lower compressive strength and poorer energy dissipation. Therefore, many theoretical and engineering application problems remain to be solved. Further experimental and theoretical studies still need to be conducted, such as the interaction between the in-plane and out-of-plane failure of masonry walls, collapse resistant of masonry walls, the seismic performance of masonry structures, and the influence of infill masonry walls on the seismic performance of RC frames.

\section{Data Availability}

All data, models, and code generated or used during the study appear in the submitted article.

\section{Conflicts of Interest}

The authors declare no conflicts of interest.

\section{Acknowledgments}

Supports for this research from the High Level Talent Support Plan (XJ17T08), Special Scientific Research Plan of Education Department in Shaanxi Province (18JK1198), National Natural Science Foundation of China (51978076), and Youth Program of National Natural Science Foundation of China (51708037) are gratefully acknowledged.

\section{References}

[1] N. Z. Yin, X. G. Zhang, and F. S. Song, Fired Brick-Tile Technology, China Architecture and Building Press, Beijing, China, 1983, in Chinese.

[2] N. N. Xu, "On destruction of solid clay brick to land resources and countermeasures," Journal of Henan University of Urban Construction, vol. 19, pp. 16-17, 2010, in Chinese.

[3] M. B. Diop and M. W. Grutzeck, "Low temperature process to create brick," Construction and Building Materials, vol. 22, no. 6, pp. 1114-1121, 2008.

[4] V. Alecci, G. Stipo, A. La Brusco, M. De Stefano, and L. Rovero, "Estimating elastic modulus of tuff and brick 
masonry: a comparison between on-site and laboratory tests," Construction and Building Materials, vol. 204, pp. 828-838, 2019.

[5] R. Agliata, T. A. Bogaard, R. Greco, L. Mollo, E. C. Slob, and S. C. Steele-Dunne, "Non-invasive estimation of moisture content in tuff bricks by GPR," Construction and Building Materials, vol. 160, pp. 698-706, 2018.

[6] L. Luo, K. Li, W. Fu, C. Liu, and S. Yang, "Preparation, characteristics and mechanisms of the composite sintered bricks produced from shale, sewage sludge, coal gangue powder and iron ore tailings," Construction and Building Materials, vol. 232, p. 117250, 2020.

[7] G. H. M. J. S. D. Silva and B. V. A. Perera, "Effect of waste rice husk ash (RHA) on structural, thermal and acoustic properties of fired clay bricks," Journal of Building Engineering, vol. 18, pp. 252-259, 2018.

[8] N. Phonphuak, C. Saengthong, and A. Srisuwan, "Physical and mechanical properties of fired clay bricks with rice husk waste addition as construction materials," Materials Today: Proceedings, vol. 17, pp. 1668-1674, 2019.

[9] O. Kizinievič, V. Kizinievič, I. Pundiene et al., "Eco-friendly fired clay brick manufactured with agricultural solid waste," Archives of Civil and Mechanical Engineering, vol. 18, pp. 1156-1165, 2018.

[10] A. N. Adazabra, G. Viruthagiri, and N. Shanmugam, "Infrared analysis of clay bricks incorporated with spent shea waste from the shea butter industry," Journal of Environmental Management, vol. 191, pp. 66-74, 2017.

[11] M. J. Munir, S. M. S. Kazmi, Y.-F. Wu, A. Hanif, and M. U. A. Khan, "Thermally efficient fired clay bricks incorporating waste marble sludge: an industrial-scale study," Journal of Cleaner Production, vol. 174, pp. 1122-1135, 2018.

[12] D. Eliche-Quesada, J. A. Sandalio-Pérez, S. MartínezMartínez, L. Pérez-Villarejo, and P. J. Sánchez-Soto, "Investigation of use of coal fly ash in eco-friendly construction materials: fired clay bricks and silica-calcareous non fired bricks," Ceramics International, vol. 44, no. 4, pp. 4400-4412, 2018.

[13] A. Mobili, C. Giosuè, and F. Tittarelli, "Valorisation of GRP dust waste in fired clay bricks," Advances in Civil Engineering, vol. 2018, Article ID 5256741, 9 pages, 2018.

[14] G. Yu, Advantages and Development Direction of Fired Shale Blocks, pp. 23-24, Brick and Tile World, Beijing, China, 2006, in Chinese.

[15] J. Parras, C. Sánchez-Jimeńez, M. Rodas, and F. J. Luque, "Ceramic applications of middle ordovician shales from central Spain,” Applied Clay Science, vol. 11, no. 1, pp. 25-41, 1996.

[16] M. Hajjaji and A. Khalfaoui, "Oil shale amended raw clay: firing transformations and ceramic properties," Construction and Building Materials, vol. 23, no. 2, pp. 959-966, 2009.

[17] X.-G. Li, Y. Lv, B.-G. Ma, S.-W. Jian, and H.-B. Tan, "Influence of sintering temperature on the characteristics of shale brick containing oil well-derived drilling waste," Environmental Science and Pollution Research, vol. 18, no. 9, pp. 1617-1622, 2011.

[18] H. W. Liu, "Effect of temperature on the quality of city sewage sludge shale brick products," Advanced Materials Research, vol. 790, pp. 316-319, 2013.

[19] I. M. Griffin, C. Hall, and A. Hamilton, "Unusual water transport properties of some traditional Scottish shale bricks," Materials and Structures, vol. 47, no. 10, pp. 1761-1771, 2014.
[20] H. L. Xie, Research and Application of Self-Insulation System of Fired-Shale Hollow Brick (Master Thesis), Chongqing University, Chongqing, China, 2012, in Chinese.

[21] Chinese Building Press, Fired Hollow Bricks and Blocks, Chinese Building Press, Beijing, China, 2014.

[22] J. Wu, G.-1. Bai, H.-y. Zhao, and X. Li, "Mechanical and thermal tests of an innovative environment-friendly hollow block as self-insulation wall materials," Construction and Building Materials, vol. 93, pp. 342-349, 2015.

[23] A. H. Salmanpour, N. Mojsilović, and J. Schwartz, "Displacement capacity of contemporary unreinforced masonry walls: an experimental study," Engineering Structures, vol. 89, pp. 1-16, 2015.

[24] H. U. Sajid, M. Ashraf, Q. Ali, and S. H. Sajid, "Effects of vertical stresses and flanges on seismic behavior of unreinforced brick masonry," Engineering Structures, vol. 155, pp. 394-409, 2018.

[25] B. Chi, X. Yang, F. Wang, Z. Zhang, and Y. Quan, "Experimental investigation into the seismic performance of fully grouted concrete masonry walls using new prestressing technology," Applied Sciences, vol. 9, no. 20, p. 4354, 2019.

[26] D. Markulak, I. Radić, and V. Sigmund, "Cyclic testing of single bay steel frames with various types of masonry infill," Engineering Structures, vol. 51, pp. 267-277, 2013.

[27] G. Wang, Y. Li, N. Zheng, and J. M. Ingham, “Testing and modelling the in-plane seismic response of clay brick masonry walls with boundary columns made of precast concrete interlocking blocks," Engineering Structures, vol. 131, pp. 513-529, 2017.

[28] P. Ramírez, C. Sandoval, and J. L. Almazán, “Experimental study on in-plane cyclic response of partially grouted reinforced concrete masonry shear walls," Engineering Structures, vol. 126, pp. 598-617, 2016.

[29] X. Zhou, J. Du, Q. Peng, and P. Chen, "Hollow block masonry wall reinforced by built-in structural configuration: seismic behavior analysis," Soil Dynamics and Earthquake Engineering, vol. 126, p. 105815, 2019.

[30] H. M. S. Eldin, A. Ashour, and K. Galal, "Seismic performance parameters of fully grouted reinforced masonry squat shear walls," Engineering Structures, vol. 187, pp. 518-527, 2019.

[31] C. Liu, X. Nong, F. Zhang, Z. Quan, and G. Bai, "Experimental study on the seismic performance of recycled concrete hollow block masonry walls," Applied Sciences, vol. 9, no. 20, p. 4336, 2019.

[32] M. Marvros, F. Ahmadi, P. B. Shing et al., "Shake-table tests of a full-scale two-story shear-dominated reinforced masonry wall structure," Journal of Structural Engineering, vol. 142, Article ID 04016078, 2016.

[33] M. T. De Risi, C. Del Gaudio, P. Ricci, and G. M. Verderame, "In-plane behaviour and damage assessment of masonry infills with hollow clay bricks in RC frames," Engineering Structures, vol. 168, pp. 257-275, 2018.

[34] A. Furtado, H. Rodrigues, A. Arêde, and H. Varum, "Influence of the in plane and out-of-plane masonry infill walls" interaction in the structural response of RC buildings," Procedia Engineering, vol. 114, pp. 722-729, 2015.

[35] A. Furtado, H. Rodrigues, H. Varum, and A. Costa, "Evaluation of different strengthening techniques' efficiency for a soft storey building," European Journal of Environmental and Civil Engineering, vol. 21, no. 4, pp. 371-388, 2015.

[36] L. Hermanns, A. Fraile, E. Alarcón, and R. Álvarez, "Performance of buildings with masonry infill walls during the 2011 Lorca earthquake," Bulletin of Earthquake Engineering, vol. 12, no. 5, pp. 1977-1997, 2014. 
[37] F. Luca, G. Verderame, F. Goméz-Martinez, and A. PérezGarcía, "The structural role played by masonry infills on RC buildings performaces after the 2011 Lorca, Spain, earthquake," Bulletin of Earthquake Engineering, vol. 12, pp. 1999-2026, 2014.

[38] J. Wu, G.-1. Bai, P. Wang, and Y. Liu, "Mechanical properties of a new type of block made from shale and coal gangue," Construction and Building Materials, vol. 190, pp. 796-804, 2018.

[39] Chinese Building Press, Standard for Test Method of Performance on Building Mortar, Chinese Building Press, Beijing, China, 2009.

[40] Chinese Building Press, Code for Design of Masonry Structures, Chinese Building Press, Beijing, China, 2011.

[41] Chinese Building Press, Code for Seismic Design of Buildings, Chinese Building Press, Beijing, China, 2010.

[42] R. Park, "Ductility evaluation from laboratoty and analytical testing," in Proceedings of the 9th World Conference on Earthquake Engineering, pp. 605-616, Tokyo, Japan, August 1988. 